\title{
Evaluation of Vibration-based Global Structural Health Monitoring Method for Medium-rise Buildings
}

\author{
Liga Gaile \\ Faculty of Civil Engineering, Institute of Civil Engineering \\ and Reconstruction \\ Riga Technical University \\ Riga, Latvia \\ Liga.gaile_1@rtu.lv
}

\author{
Ivars Radins \\ Faculty of Civil Engineering, Institute of Civil Engineering \\ and Reconstruction \\ Riga Technical University \\ Riga, Latvia \\ ivars.radins@rtu.lv
}

\begin{abstract}
The automated monitoring of a building's structural health during its exploitation is a way to extend its design life without compromising structural safety. In turn, it helps increase the rate of building renovation works compared to demolition works, which reduces future construction and demolition waste levels.

This research explores the vibration-based global monitoring method application to structurally stiff mediumrise reinforced concrete buildings by analysing predicted building vibration amplitudes and spectrum under regular city traffic excitation. These predictions are based on the results obtained from finite element calculations of building models with variated structural stiffness and inertial mass of the building.
\end{abstract}

Regular traffic-generated ground frequency spectrum differs from the first natural frequencies of medium-rise reinforced concrete buildings, and the vibration energy is low. Nevertheless, it is found that the structural identification of such building dynamic parameters is still possible, particularly natural frequencies. It was found that the ratio between fundamental frequency for the fixed base model of the building and elastic spring foundation model is the decisive parameter for selecting the building part to be monitored. Structural health monitoring vibration-based methods are also a promising technology for medium-rise mass house buildings when tailored according to some damage sensitive feature.

Keywords - Medium-rise building, Structural Health Monitoring, Vibration-based method.

\section{INTRODUCTION}

The significant adverse effect of the construction industry on the environment is a generation of construction waste $(\mathrm{CW})$. One of the strategies to reduce $\mathrm{CW}$ is an extension of building service life [1]. Nowadays, the design life of a building generally does not exceed 50 to 60 years, but it also does not mean that it becomes structurally unsound after this period. According to EC0 [2], it is just an "assumed period for which a structure or part of it is to be used for its intended purpose with anticipated maintenance but without major repair being necessary".

The rapidly developing field of Structural health monitoring (SHM) could help implement justified decisions when the repair of the structure is necessary due to safety issues. SHM is regarded as a process of implementing a damage detection strategy that involves the observation of a structure over time using real-time or periodically spaced and preferably automated dynamic response measurements, the extraction of damagesensitive features from these measurements and the statistical analysis of these features to determine the current state of structural system health [3].

According to researchers D. M. Frangopol and T.B. Messervey, SHM it is also a powerful and necessary mechanism to reduce uncertainty, to calibrate, and to improve structural assessment and performance of prediction models [4]. Without monitoring information, inaccurate prediction of future performance might cause tremendous consequences due to failure occurrences if later reaching of prescribed performance threshold is 
predicted [5]. As indicated in Fig. 1, service life can be prolonged if SHM is performed.

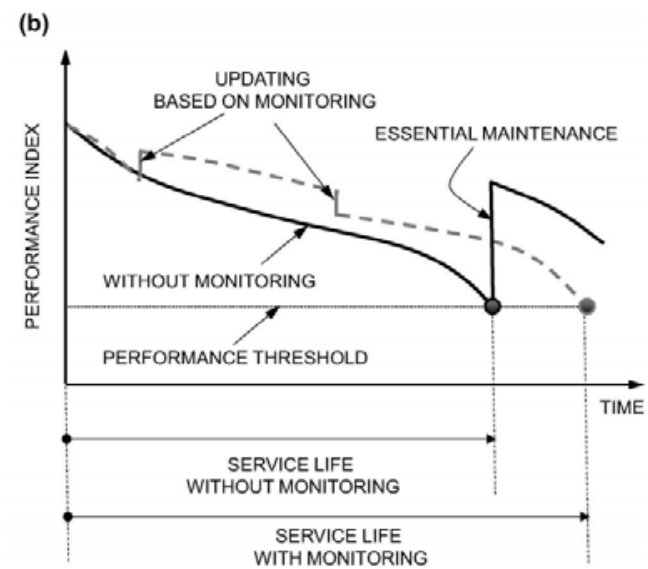

Fig. 1. Performance index profile with and without monitoring (service life with monitoring larger than service life without monitoring) [5]

SHM strategies are divided into two main groups that provide different type of information - local and global strategies. Global SHM methods attempt to simultaneously assess the condition of the whole structure and mainly use vibration-based methods. Successful implementations of such methods have been implemented in major civil infrastructure projects like bridges, stadiums, high-rise structures or underground facilities [6]

SHM system generally consists of five key aspects [7]:

- Sensors and sensing technology,

- Diagnostic signal generation,

- Signal transmission and processing,

- Event identification and interpretation,

- Integration into an operative system for systems life management.

In the case of a medium-rise building, vibration-based monitoring as a diagnostic signal ambient vibrations of the ground are used. As opposed to large and flexible structures, the vibration of such buildings characterises with very low amplitudes of vibrations and main excitors under ambient conditions, is microtremors originating from human activities. Those microtremors are dominated by the components with a frequency higher than $1 \mathrm{~Hz}$ [8] as opposed to natural phenomenon like the wind. Experimentally obtained and published case study data from references [9]-[11] shows that most experimentally obtained fundamental frequencies of low and mid-rise buildings with less than 16 floors lies in the range of $1 \mathrm{~Hz}$ to $4 \mathrm{~Hz}$. Fig. 2 presents a graphical display in which the area of boxes of the plot is proportional to the contingency table's cell frequencies. If the building's average storey height is taken as $4 \mathrm{~m}$, it follows that the majority of buildings with four floors and less have a fundamental frequency of more than $3,6 \mathrm{~Hz}$. Buildings with a storey height of more than ten floors have a fundamental frequency of less than $1,7 \mathrm{~Hz}$.

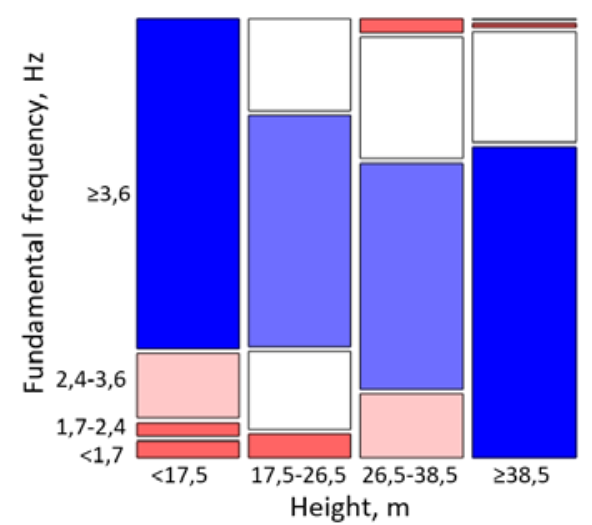

Fig. 2. A mosaic plot of fundamental frequency distributions of buildings (based on data from publications [9]-[11])

The variance of the fundamental frequencies in Fig. 2 is mainly due to two reasons. Firstly, there is considerable variability of possible plan dimensions and configurations of low and mid-rise buildings. Secondly, the soil-structure interaction (SSI) effect plays a significant role.

A convenient way to determine the SSI effect on building frequencies is the use of a relative measure $\mathrm{h} /(\mathrm{VsT})$ [12]. Here height, $\mathrm{h}$, is the effective height to the centre of mass for the first mode shape, taken as approximately two-thirds of the modelled building height. Vs is shear wave velocity that should be taken as the average effective profile velocity calculated based on overburden-corrected shear wave velocities below the foundation. $\mathrm{T}$ is a building's period taken as the best estimate value of the fixed-based building period in the direction under consideration. Therefore, for low and midrise buildings where the building's height is low, this relative measure is more than 0.1 , which is the criteria for the importance of SSI effect. In this case, SSI effect significantly lengthens the building period, modifies damping in the system and distribution of the force and deformation within the structure compared to the fixed base analysis.

On the other hand, the building's vibration amplitudes are heavily dependent on the building vibration source's spectral characteristics relative to the building's dynamic parameters. Authors' previous research [13] experimentally studied the spectral characteristics and ground vibration amplitudes for ambient vibration source regular traffic. It was found that site power spectrum contains more considerable energy input in frequencies from $10-15 \mathrm{~Hz}$ and vertical component of ground vibration amplitude $30 \mathrm{~m}$ from vibration source is in order of $10^{-4}$ to $10^{-5}$. Nevertheless, it seems like for low and mid-rise buildings in response to a typical traffic spectrum, low vibration modes are still excited [14].

For structural damage event identification and interpretation, a vast amount of methods is proposed. However, these methods are only applicable when a prior quality modal identification is performed. From experimental measurements structural mode shapes are 
obtained as well as corresponding natural frequencies and preferably damping ratios.

This research investigates the prospects of applying vibration-based methods for structural health monitoring of stiff medium-rise buildings like cellular or shear wall buildings. The possible effect of soil-structure interaction on building natural frequencies and mode shapes was numerically analysed and the possibilities to perform structural identification of modal parameters for five-story reinforced concrete (RC) buildings with a cellular structure were explored. The building was excited by low-level ambient vibration with an experimentally obtained spectrum characteristic to regular traffic. Structural identification was made using several structural identification methods for two cases: dynamic response of building without introducing sensor noise and introducing sensor noise when the signal-to-noise ratio is 10 .

It was found that the ratio between fundamental frequency for the fixed base model of the building and elastic spring foundation model is the decisive parameter for selecting building the part to be monitored.

Additionally, this paper summarises some of the published full-scale experimental research results about building mode shape spectrum, which is essential prior information when mode shape identification is made from noisy sensor records in real-world applications.

\section{CHARACTERISTIC MODE SHAPES OF MEDIUM-RISE BUILDINGS}

It is advantageous to know information about characteristic mode shapes depending on the building's geometry before analysing noisy sensor records in realworld applications. As shown in the example in the next section of the paper, depending on the precision of the FEM model, mode shapes can take places in a different order that makes identification of higher mode shapes in the experimental data challenging, especially from records of ambient vibrations.

In Table 1, frequency ratios of mode shapes have been calculated (relevant mode shape frequency to fundamental mode shape frequency) obtained from experimental results published in the literature.

When a building behaves like a pure cantilever (pure bending) with a fixed base for transversal mode, this ratio is theoretically $1,6.27$ and 17.55 . But for buildings that behave as a pure shear beam, this ratio theoretically is 1,3 and 5.

It is found that very seldom second (lateral, longitudinal and torsional) global mode shape frequencies for low and medium-rise buildings from full-scale experiments are reported in published literature. Nevertheless, it is clear from the data that mid-rise RC frame buildings behave almost like a pure shear beam. Table 1 also reveals the existence of closely spaced modes. Closely spaced modes arise in structures from geometrical effects such as symmetry or torsional unbalance [15].

TABLE 1 THE RATIO OF NATURAL FREQUENCY AND FUNDAMENTAL FREQUENCY DEPENDING ON THE NUMBER OF STORIES AND MODE

\begin{tabular}{|c|c|c|c|c|c|c|c|}
\hline \multirow{2}{*}{$\begin{array}{l}\text { Nr. of stories } \\
\text { (struct. } \\
\text { material) }\end{array}$} & \multirow{2}{*}{$\begin{array}{l}\text { Approx. plan } \\
\text { dimension ratio }\end{array}$} & \multirow{2}{*}{$\begin{array}{c}\text { Fundam } \\
\text { ental } \\
\text { freq., } \mathrm{Hz}\end{array}$} & \multirow{2}{*}{$\sum^{\frac{0}{g}}$} & \multicolumn{3}{|c|}{$\begin{array}{l}\text { Normalised frequency to fundamental frequency of building } \\
\text { (natural frequency } \boldsymbol{i} \text { /fundamental freq.) }\end{array}$} & \multirow{2}{*}{ Ref. } \\
\hline & & & & Lateral mode shape & $\begin{array}{c}\text { Longitudinal mode } \\
\text { shape }\end{array}$ & $\begin{array}{l}\text { Torsional mode } \\
\text { shape }\end{array}$ & \\
\hline 15 (RC) & $\begin{array}{l}1: 1.85 \\
\text { (upper part) }\end{array}$ & 0.76 & $\begin{array}{l}1^{\text {st }} \\
2^{\text {nd }} \\
3^{\text {rd }} \\
\end{array}$ & $\begin{array}{c}1 \\
2.93 \\
5.06 \\
\end{array}$ & $\begin{array}{r}1.11 \\
3.23 \\
5.59 \\
\end{array}$ & $\begin{array}{c}1.46 \\
3.86 \\
5.9 \\
\end{array}$ & [16] \\
\hline 7 (RC) & $1: 2$ & 2.37 & $1^{\text {st }}$ & 1 & 1.16 & 1.41 & [17] \\
\hline $48(\mathrm{RC})$ & $\begin{array}{c}1: 2.1 \\
\text { (“eye” shape) }\end{array}$ & 0.28 & $\begin{array}{l}1^{\text {st }} \\
2^{\text {nd }}\end{array}$ & $\begin{array}{c}1 \\
4.39 \\
\end{array}$ & $\begin{array}{l}1.72 \\
6.85\end{array}$ & $\begin{array}{l}2.45 \\
7.28\end{array}$ & [18] \\
\hline $4(\mathrm{M})$ & 1:1.05 & 2.56 & $\begin{array}{l}1^{\text {st }} \\
2^{\text {nd }}\end{array}$ & $\begin{array}{c}1 \\
3.46\end{array}$ & $\begin{array}{l}1.08 \\
3.59\end{array}$ & $\begin{array}{l}2.79 \\
5.94\end{array}$ & [19] \\
\hline 15(RC) & $\begin{array}{c}1: 3.4 \\
\text { (upper part) }\end{array}$ & 1.16 & $1^{\text {st }}$ & 1 & 1.05 & 1.25 & [20] \\
\hline $4(\mathrm{RC})$ & $1: 3.7$ & 3.51 & $1^{\mathrm{st}}$ & 1 & 1.12 & 1.1 & [21] \\
\hline 8 (RC) & 1:3.1 & 2.1 & $1^{\mathrm{st}}$ & 1 & 1.07 & 1.1 & [22] \\
\hline 9 (RC) & $\begin{array}{c}1: 2.5 \\
\text { (upper part) }\end{array}$ & 1.95 & $1^{\text {st }}$ & 1 & 1.24 & 1.69 & [23] \\
\hline 5 (RC) & $\begin{array}{c}1: 1.5 \\
\text { (upper part) }\end{array}$ & 1.15 & $\begin{array}{l}1^{\text {st }} \\
2^{\text {nd }}\end{array}$ & $\begin{array}{c}1 \\
3.4 \\
\end{array}$ & $\begin{array}{c}1.33 \\
- \\
\end{array}$ & $\begin{array}{l}1.43 \\
3.69 \\
\end{array}$ & [24] \\
\hline $32(\mathrm{RC})$ & $\begin{array}{c}1: 1.1 \\
\text { (upper part) }\end{array}$ & 0.55 & $\begin{array}{l}1^{\text {st }} \\
2^{\text {nd }} \\
\end{array}$ & $\begin{array}{c}1 \\
4.23 \\
\end{array}$ & $\begin{array}{c}1.18 \\
5.3 \\
\end{array}$ & $\begin{array}{l}2.34 \\
6.65 \\
\end{array}$ & [25] \\
\hline
\end{tabular}


These case studies show - buildings with a plan dimensions close to a square have closely spaced first lateral and longitudinal mode shapes as expected. Still, buildings with rectangular plan dimensions could have closely spaced first longitudinal and first torsional mode shape. Torsional mode shapes other are usually well separated from each.

Operational Modal Analysis (OMA) on collected data was used to obtain these mode shapes experimentally. The reviewed papers of full-scale in-situ case studies mostly used high precision force balanced accelerometers and servo-type accelerometers for data collection. The most often chosen sampling rate was $100 \mathrm{~Hz}$ for frequencies of interest between 0,1 and $20 \mathrm{~Hz}$. Accelerometers have an input range of $\pm 0,5 \mathrm{~g} ; \pm 1 \mathrm{~g}$ or $\pm 2 \mathrm{~g}$ and sensitivities $2 \mathrm{~V} / \mathrm{g}$ or $10 \mathrm{~V} / \mathrm{g}$. Most often, the duration of one record is $10-15$ $\mathrm{min}$. The frequency and volume of collected data depended on the relevant investigation aims.

Different time domain and frequency domain identification techniques for estimation of modal parameters was successfully applied to case study buildings. Among the most popular and usually used in pairs to be able to verify the correctness of the obtained results are Frequency Domain Decomposition (FDD); Enhanced Frequency Domain Decomposition (EFDD); Stochastic Subspace Identification (SSI); Stochastic Subspace Identification - Unweighted principal component (SSI-UPC); Peak-Piking (PP).

\section{MATERIALS AND METHODS}

Overall, buildings behave like a Timoshenko beam with properties between a pure shear beam and a pure bending beam. The soil-structure interaction should not be neglected in determining the dynamic behaviour of buildings [26].

For the SSI effect investigation a FEM model of an existing apartment building with strip foundations (see Fig. 3 and Fig.4) was prepared. In the first model, foundation stiffness is considered by modelling vertical springs according to the soil description given in Table 2 . The second model does not take foundation stiffness into account, and supports are modelled as pinned. The total mass of the building for dynamic analysis is $3704.4 \mathrm{t}$.

Analysis of traffic-induced ground vibration is a very complicated problem because it involves a vast number of unknown factors. Therefore, further in the assessment of building dynamic response, several assumptions and simplifications were made.

An experimentally obtained ground acceleration time series is used to assess this building's dynamic response to typical normal traffic-induced ambient vibrations. The time series were obtained in previous research of the authors [13]. Most of the energy generated at the ground surface from traffic is transmitted as Rayleigh surface waves [27]. Rayleigh wave velocity is independent of the exiting frequency and can be derived as a fraction of the shear wave velocity for rocks and soils. Generally, it is a factor of 0.9 - 0.95 of shear wave velocities [28] but soil shear wave velocities can vary from $100 \mathrm{~m} / \mathrm{s}$ to $1500 \mathrm{~m} / \mathrm{s}$ depending on clay content, porosity, water content and overburden depending. The Rayleigh wave particle velocity is perpendicular to the direction of the wave propagation. Therefore, two components appear-in the plane and perpendicular to it to the foundation on an elastic support should be applied.

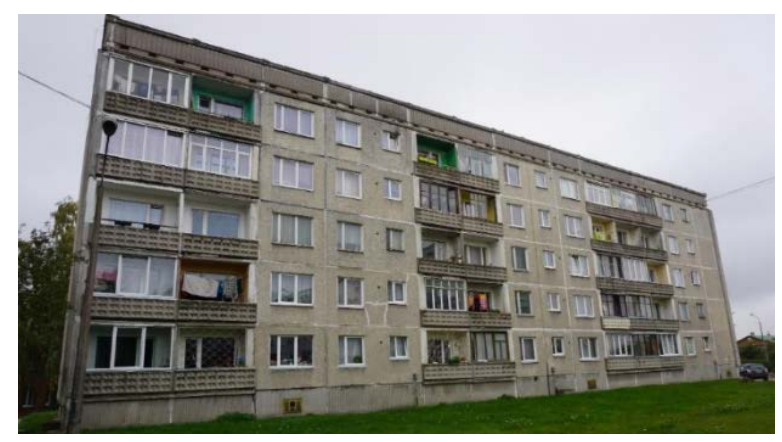

Fig. 3. Apartment building (464 series)

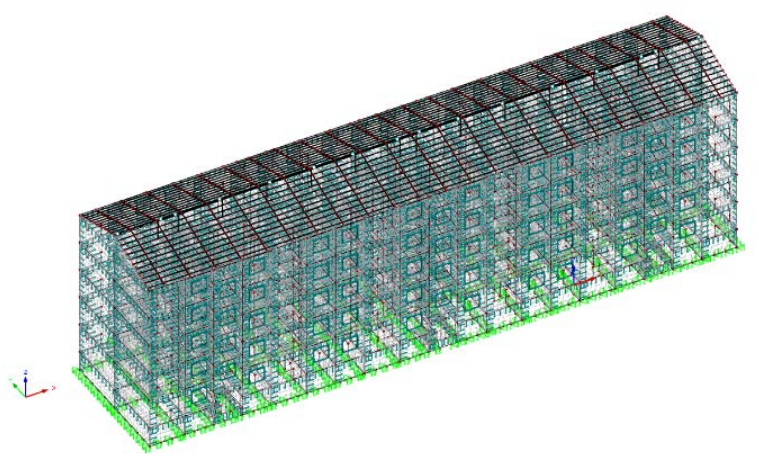

Fig. 4. FEM model of apartment building (464 series)

TABLE 2 DESCRIPTION OF SOIL

\begin{tabular}{|c|c|c|c|c|c|}
\hline \multirow{2}{*}{$\begin{array}{c}\text { Layer } \\
\#\end{array}$} & \multirow{2}{*}{$\begin{array}{c}\Delta t \\
{[\mathbf{m}]}\end{array}$} & \multicolumn{2}{|c|}{ Specific weight } & \multirow{2}{*}{$\begin{array}{c}\mathbf{E}_{\text {def }} \\
{\left[\mathbf{M N} / \mathbf{m}^{2}\right]}\end{array}$} & \multirow{2}{*}{$v$} \\
\hline & & $\begin{array}{c}\gamma \\
{\left[\mathrm{kN} / \mathrm{m}^{3}\right]}\end{array}$ & $\begin{array}{c}\gamma_{\text {sat }} \\
{\left[\mathbf{k N} / \mathbf{m}^{3}\right]}\end{array}$ & & \\
\hline 1. & 0,8 & 17,20 & 19,60 & 30,00 & 0,30 \\
\hline 2. & 2,5 & 18,80 & 19,60 & 34,00 & 0,30 \\
\hline 3. & 2,0 & 17,20 & 19,60 & 20,00 & 0,30 \\
\hline 4. & 8,7 & 18,50 & 20,30 & 18,00 & 0,30 \\
\hline \multicolumn{6}{|c|}{$\begin{array}{l}\Delta \mathrm{t}-\text { layer thickness; } \mathrm{E}_{\mathrm{def}}-\text { mod. of elasticity; } v \text { - Poisson's r.; } \\
\text { Layer \#1. Medium coarse, medium dense sand } \\
\text { Layer \#2. Loamy fine, medium dense sand } \\
\text { Layer \#3. Silty, fine-medium dense sand } \\
\text { Layer \#4. Silty dense sand }\end{array}$} \\
\hline
\end{tabular}

The constructed FEM model of the building has 66068 node points. Therefore, the application of ground acceleration time series to the flexible supports would result in the same number of time series that takes considerable computer resources even for a few minutes of computer simulations. Therefore, the equivalent frame model is used in the calculations further and is presented in Fig. 5. In this model, fundamental frequency when 
Environment. Technology. Resources. Rezekne, Latvia Proceedings of the $13^{\text {th }}$ International Scientific and Practical Conference. Volume 1, 55-61

pinned supports is used is $11 \mathrm{~Hz}$, but when spring supports are used $-3,7 \mathrm{~Hz}$. Damping of the fundamental mode is taken as $5 \%$. The reference model for simulations is taken as a frame model with proportionally reduced total mass and stiffness compared to the full 3D FEM model. An example of an applied ground accelerogram to the foundation is demonstrated in Fig. 6.

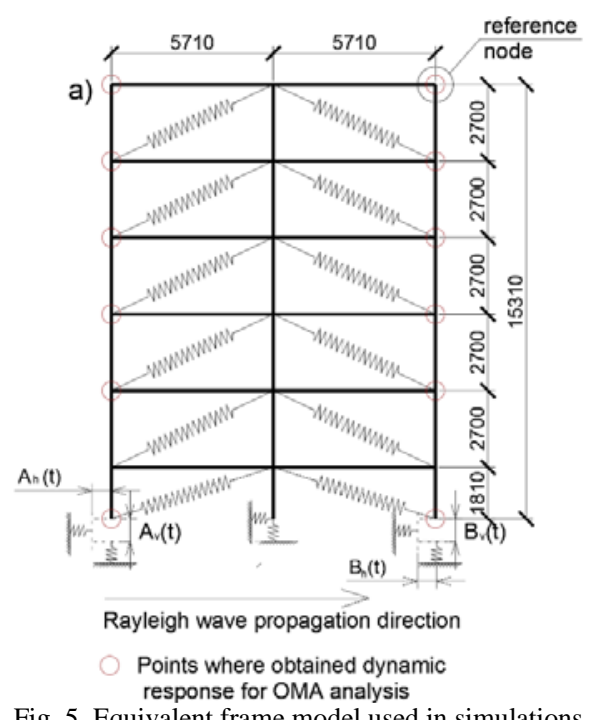

Fig. 5. Equivalent frame model used in simulations

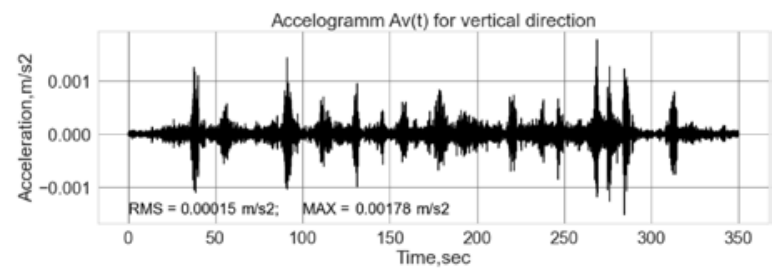

Fig. 6. Example of applied ground accelerogram to the foundation

Accelerograms $A_{v}(t), A_{h}(t), B_{v}(t)$ and $B_{h}(t)$ were recorded simultaneously with a sample rate of $400 \mathrm{~Hz}$ and bandwidth after data filtration of $0.8-35 \mathrm{~Hz}$. Time series $\mathrm{A}(\mathrm{t})$ were recorded $15 \mathrm{~m}$ from the traffic lane, and $\mathrm{B}(\mathrm{t})$ were recorded $30 \mathrm{~m}$ from the traffic lane. Information about these accelerograms is available in the reference [13]. Then time series were down-sampled to $50 \mathrm{~Hz}$ (Nyquist freq $=25 \mathrm{~Hz}$ ) to reduce required storage space and run time for simulation results.

\section{MEDIUM-RISE BUILDING DYNAMIC RESPONSE TO TRAFIC AND IDENTIFICATION OF MODAL DATA}

\section{A. Effect of soil-structure interaction}

Results from full 3D FEM model numerical calculations of apartment building modal parameters are summarised in Table 3. - 4.

Firstly, the ratio between the first and second model's fundamental frequencies is almost three times; secondly, there is a big difference in the effective modal mass factor for the stiffest translational direction that highlights the differences in mode shapes. The effective modal mass factor describes how much mass is activated by each eigenvalue of the system in each direction.

TABLE 3 FREQUENCIES AND EFFECTIVE MODAL MASS FACTORS

\begin{tabular}{|c|c|c|}
\hline \multicolumn{3}{|c|}{ FEM model 1 -elastic spring foundation } \\
\hline Structural mode (\#) & Frequency, $\mathrm{Hz}$ & $\begin{array}{c}\text { The effective } \\
\text { modal mass factor } \\
\text { for relevant } \\
\text { direction }\end{array}$ \\
\hline $\begin{array}{c}1^{\text {st }} \text { transverse mode } \\
\text { (1) }\end{array}$ & 3,75 & 0,604 \\
\hline $\begin{array}{l}1^{\text {st }} \text { torsional mode } \\
\text { (2) }\end{array}$ & 7,00 & NA \\
\hline $\begin{array}{l}1^{\text {st }} \text { longitudinal } \\
\text { mode (3) }\end{array}$ & 7,43 & 0,303 \\
\hline $\begin{array}{l}\text { Soil and building } \\
\text { vertical (4) }\end{array}$ & 9,07 & 0,918 \\
\hline \multicolumn{3}{|c|}{$\begin{array}{l}\text { Follows } 38 \text { local modes with frequencies from } 9.9 \mathrm{~Hz} \text { to } 13,3 \\
\text { (with an average modal mass of local mode is approx. } 4 \mathrm{t} \text { ) }\end{array}$} \\
\hline $\begin{array}{l}2^{\text {nd }} \text { torsional mode } \\
(43)\end{array}$ & 13,3 & NA \\
\hline \multicolumn{3}{|c|}{$\begin{array}{c}\text { Follows } 39 \text { local modes with frequencies from } 13,4 \text { to } 17,6 \\
\text { (average modal mass of local mode is } 2.1 \mathrm{t} \text { ) }\end{array}$} \\
\hline $\begin{array}{l}2^{\text {nd }} \text { vertical mode } \\
\text { (83) }\end{array}$ & 19,6 & NA \\
\hline
\end{tabular}

TABLE 4 FREQUENCIES AND EFFECTIVE MODAL MASS FACTORS

\begin{tabular}{|c|c|c|}
\hline \multicolumn{3}{|c|}{ FEM model 2 - the fixed foundation } \\
\hline Structural mode (\#) & Frequency, $\mathbf{H z}$ & $\begin{array}{c}\text { The effective } \\
\text { modal mass factor } \\
\text { for relevant } \\
\text { direction }\end{array}$ \\
\hline \multicolumn{2}{|c|}{ Starts with 20 local modes } \\
\hline $\begin{array}{c}1^{\text {st }} \text { transverse mode } \\
(21)\end{array}$ & 11,05 & 0,605 \\
\hline $\begin{array}{c}1^{\text {st }} \text { longitudinal } \\
\text { mode (34) }\end{array}$ & 12,64 & 0,611 \\
\hline $1^{\text {st }} \begin{array}{c}\text { torsional mode } \\
(37)\end{array}$ & 12,81 & NA \\
\hline
\end{tabular}

Note: NA - not applicable or not obtained, \# - consecutive number of mode.

\section{B. Dynamic response of building}

When a ground acceleration time series is applied in the manner described in the previous section, reference node maximum and RMS accelerations and Power spectral density (PSD) spectrum values are reflected in Table 5.

Table 5 shows the maximum dynamic response in lateral direction, but comparable amplitudes are also obtained for the vertical direction, which indicates the building's rocking motion. Reference model stiffness or mass changes resulted in different fundamental frequency values that are still in line with typical fundamental frequencies of buildings showed in Fig 2.

The simulations revealed that when there is a big difference between fundamental frequency for a fixed foundation model of building and elastic spring foundation model, the modal frequency is not a sensitive parameter for SHM purposes of the structure itself. Therefore, this ratio is a decisive parameter for selecting building part to be monitored. This feature might be useful for a very stiff 
structure to detect sudden changes in the geological situation under the building base. For example, early detection of hazard in the zones where there is a risk of karst formation. However, for buildings where this ratio is close to one, monitoring of structural changes would be possible.

TABLE 5 DYNAMIC RESPONSE OF THE EQUIVALENT MODEL

\begin{tabular}{|c|c|c|c|}
\hline \multicolumn{4}{|c|}{ Equivalent model dynamic response to accelerograms } \\
\hline $\begin{array}{c}\text { Model } \\
\#\end{array}$ & $\begin{array}{c}\text { Fund. } \\
\text { frequency of } \\
\text { the model, Hz }\end{array}$ & $\begin{array}{c}\text { Change in } \\
\text { inertia mass } \\
\text { model,\% }\end{array}$ & $\begin{array}{c}\text { Change in } \\
\text { stiffness model,\% }\end{array}$ \\
\hline 1. & 3,74 & \multicolumn{2}{|c|}{ Reference model } \\
\hline 2. & 3,57 & - & $-50 \%$ \\
\hline 3. & 3,83 & - & $+50 \%$ \\
\hline 4. & 2,65 & $+50 \%$ & - \\
\hline 5. & 5,29 & $-50 \%$ & - \\
\hline Model & $\begin{array}{c}\text { Max response } \\
\text { peak amplitude } \\
\text { of reference } \\
\text { point, } \text { m/s2 }\end{array}$ & $\begin{array}{c}\text { Max response } \\
\text { RMS ampl. of } \\
\text { reference } \\
\text { point, } \text { m/s2 }\end{array}$ & $\begin{array}{c}\text { PSD spectrum } \\
\text { magnitude for the } \\
\text { fundamental } \\
\text { mode }\end{array}$ \\
\hline 1. & 0,0080 & 0,00081 & $2,95 \cdot 10^{-9}$ \\
\hline 2. & 0,0222 & 0,00170 & $5,54 \cdot 10^{-9}$ \\
\hline 3. & 0,0060 & 0,00071 & $3,32 \cdot 10^{-9}$ \\
\hline 4. & 0,0099 & 0,00095 & $2,11 \cdot 10^{-10}$ \\
\hline 5. & 0,0122 & 0,00091 & $5,62 \cdot 10^{-8}$ \\
\hline
\end{tabular}

Note: Foundation stiffness has not changed over simulations.

For all the cases except one acceleration RMS amplitudes of the reference point is in in order of $10^{-4}$. From results in Table 5 it follows that maximum response peak amplitude or RMS would not be a good damage sensitive feature for SHM of medium-rise buildings due to its nonsensitivity to minor or moderate changes in global stiffness.

In all cases, higher energy input in PSD spectrum from lateral modes is in the second lateral mode because it corresponds better to the applied bandwidth of mainly from $6.8 \mathrm{~Hz}$ to $16.6 \mathrm{~Hz}$ (vertical direction) and from $6.3 \mathrm{~Hz}$ to $20.7 \mathrm{~Hz}$ (horizontal direction). Nevertheless, in all cases, a fundamental mode of structure could be identified and well separated from the vibration source's bandwidth. PSD spectrum of equivalent frame reference model response for the reference point is presented in Fig. 7. and Singular Value Decomposition of all data is shown in Fig. 8.

The precision of obtained natural frequencies is better when one of the OMA identification techniques is used compared to peak picking from the PSD spectrum. Nonphysical modes can be identified by looking at mode shapes and mode complexity factor. One of the damage sensitive features is the damping ratio, but generally, it failed to be identified correctly by all the methods.

When the response signal-to-noise ratio is set to $\mathrm{S} / \mathrm{N}=10$, the structural identification accuracy for all modes on average changed from $0,74 \%$ to $1,31 \%$ (expressed as an error between theoretical and calculated results).

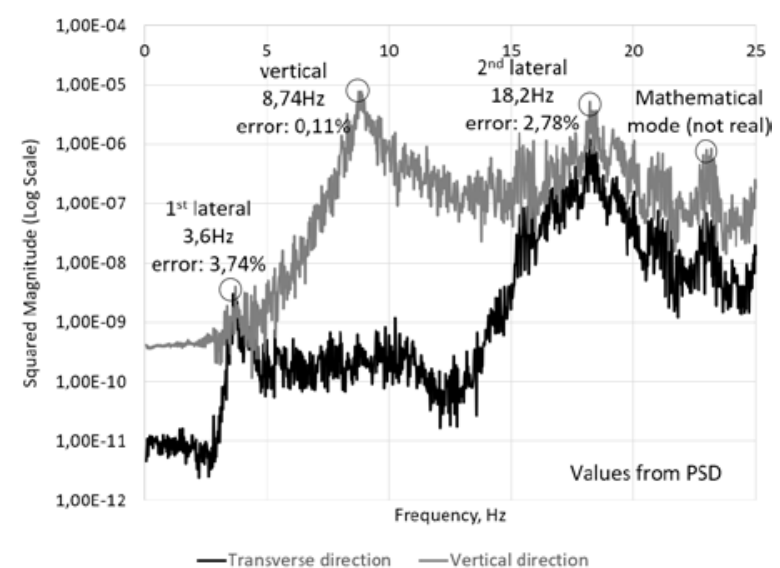

Fig. 7. Power Spectral Density of equivalent frame reference model response

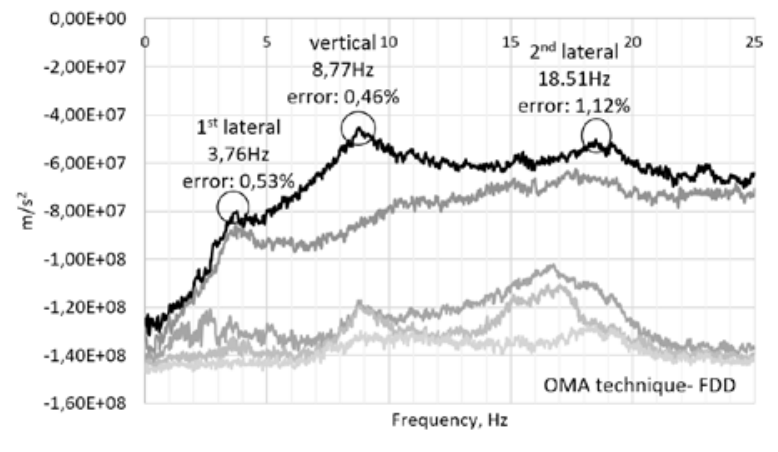

Fig. 8. Singular Value Decomposition of equivalent frame reference model response (FDD technique, no sensor noise)

TABLE 6 IDENTIFIED FREQUENCIES WITH OMA TECHNIQUE

\begin{tabular}{|c|c|c|c|c|c|}
\hline \multirow{3}{*}{$\begin{array}{l}\text { Modes } \\
\text { shape }\end{array}$} & \multirow{3}{*}{$\begin{array}{c}\text { Exact } \\
\text { from } \\
\text { FEM, } \\
\text { Hz }\end{array}$} & \multicolumn{4}{|c|}{$\begin{array}{c}\text { The identified frequency with OMA } \\
\text { technique, } \mathrm{Hz}\end{array}$} \\
\hline & & FDD & EFDD & CFDD & $\begin{array}{l}\text { SSI- } \\
\text { UPC }\end{array}$ \\
\hline & & \multicolumn{4}{|c|}{ No additional sensor noise } \\
\hline $\begin{array}{c}1^{\text {st }} \\
\text { lateral }\end{array}$ & 3,74 & 3,76 & 3,74 & 3,74 & - \\
\hline vertical & 8,73 & 8,77 & $8,91^{*}$ & 8,92 & $8,77 *$ \\
\hline $\begin{array}{c}2^{\text {nd }} \\
\text { lateral }\end{array}$ & 18,72 & 18,51 & 18,50 & 18,55 & 18,72 \\
\hline \multicolumn{6}{|c|}{ Signal to noise ratio $\mathrm{S} / \mathrm{N}=\left(\mathrm{RMS}_{\text {signal }} / \mathrm{RMS}_{\text {noise }}\right)^{2}=10$} \\
\hline $\begin{array}{c}1^{\text {st }} \\
\text { lateral }\end{array}$ & 3,74 & 3,71 & 3,69 & 3,70 & - \\
\hline vertical & 8,73 & 8,81 & $8,91^{*}$ & 8,92 & $8,85^{*}$ \\
\hline $\begin{array}{c}2^{\text {nd }} \\
\text { lateral }\end{array}$ & 18,72 & 18,51 & 18,37 & 18,52 & 18,37 \\
\hline \multicolumn{6}{|c|}{$\begin{array}{l}\text { FDD - Frequency Domain Decomposition method } \\
\text { EFDD - Enhanced Frequency Domain Decomposition } \\
\text { CFDD - Curve-fit Frequency Domain Decomposition } \\
\text { SSI-UPC - Stochastic subspace identification - Unweighted } \\
\text { principal components } \\
\text { * - correctly identified damping of 5\% }\end{array}$} \\
\hline
\end{tabular}

\section{CONCLUSIONS}

This research investigated the prospects of applying vibration-based methods for structural health monitoring of 
stiff medium-rise buildings like cellular architecture precast reinforced concrete buildings.

It was found that the ratio between fundamental frequency for the fixed base model of the building and elastic spring foundation model is the decisive parameter for selecting the building part to be monitored. In the case of a stiff medium-rise building, this ratio could be even three. Then changes in natural frequencies might be useful for detecting sudden changes in the geological situation under the building base. An application example could be early detection of hazard in the zones where there is a risk of karst formation.

The damage sensitive feature - the damping ratio - was not correctly identified with any common OMA structural identification techniques for this type of structure. Nevertheless, natural frequencies were identified correctly with a mean error across frequencies of $1,3 \%$, even with a signal-to-noise ratio as high as 10 .

\section{ACKNOWLEDGEMENT}

This work has been supported by the European Regional Development Fund within the Activity 1.1.1.2 "Post-doctoral Research Aid" of the Specific Aid Objective 1.1.1 "To increase the research and innovative capacity of scientific institutions of Latvia and the ability to attract external financing, investing in human resources and infrastructure" of the Operational Programme "Growth and Employment" (No.1.1.1.2/VIAA/3/19/393).

\section{REFERENCES}

[1] D. F. Laefer and J. P. Manke, "Building Reuse Assessment for Sustainable Urban Reconstruction,” J. Constr. Eng. Manag., 2008.

[2] “EN 1990. Eurocode-Basis of structural design.” .

[3] C. R. Farrar and K. Worden, Structural Health Monitoring: A Machine Learning Perspective. 2012.

[4] D. M. Frangopol and T. B. Messervey, "Maintenance Principles for Civil Structures," in Encyclopedia of Structural Health Monitoring, John Wiley \& Sons, Ltd, 2009.

[5] D. M. Frangopol, "Life-Cycle performance, management, and optimisation of structural systems under uncertainty: Accomplishments and challenges,” Struct. Infrastruct. Eng., 2011.

[6] H. N. Li, L. Ren, Z. G. Jia, T. H. Yi, and D. S. Li, "State-of-the-art in structural health monitoring of large and complex civil infrastructures," J. Civ. Struct. Heal. Monit., 2016.

[7] V. M. Karbhari and F. Ansari, Structural health monitoring of civil infrastructure systems. 2009.

[8] O. Kulhanek, “Anatomy of seismograms,” Anat. Seism., 1990.

[9] M. R. Gallipoli et al., "Empirical estimates of dynamic parameters on a large set of European buildings,” Bull. Earthq. Eng., 2010.

[10] R. K. Goel and A. K. Chopra, "Period formulas for momentresisting frame buildings,” J. Struct. Eng., 1997.

[11] C. S. Oliveira and M. Navarro, "Fundamental periods of vibration of RC buildings in Portugal from in-situ experimental and numerical techniques,” Bull. Earthq. Eng., 2010.
[12] NEHRP Consultants Joint Venture, Soil-Structure Interaction for Building Structures. 2012.

[13] Gaile L; Sliseris J; Ratnika L, "Towards SHM of medium-rise buildings in non-seismic areas.” Proceedings of 10th International Conference on Structural Health Monitoring of Intelligent Infrastructure - SHMII 10 (submitted), 2021.

[14] H. Hao, T. C. Ang, and J. Shen, "Building vibration to trafficinduced ground motion,” Build. Environ., 2001.

[15] C. Manu, "Dynamic analysis of structures with closely spaced modes using the response spectrum method," Comput. Struct., 1986.

[16] Y. Tamura, L. Zhang, A. Yoshida, S. Nakata, and T. Itoh, "Ambient Vibration Tests and Modal Identification of Structures by FDD and 2DOF-RD Technique,” SEWC, Yokohama, Japan, 2002.

[17] S. Kechidi and N. Bourahla, "Effective use of ambient vibration measurement for modal updating," in Les Premières Rencontres Nationales sur le Génie Civil RNGC'2014, 2014.

[18] C. E. Ventura, J.-F. Lord, and R. D. Simpson, "Effective Use of Ambient Vibration Measurements for Modal Updating of a 48 Storey Building in Vancouver, Canada," Int. Conf. "Structural Dyn. Model. Anal. Correl. Valid., 2002.

[19] L. F. Ramos, "Damage identification on masonry structures based on vibration signatures," 2007.

[20] C. Michel, P. Guéguen, S. El Arem, J. Mazars, and P. Kotronis, "Full-scale dynamic response of an RC building under weak seismic motions using earthquake recordings, ambient vibrations and modelling,” Earthq. Eng. Struct. Dyn., 2010.

[21] F. Butt and P. Omenzetter, "Long term seismic response monitoring and finite element modeling of a concrete building considering soil flexibility and non-structural components," in Sensors and Smart Structures Technologies for Civil, Mechanical, and Aerospace Systems 2011, 2011.

[22] D. Gargaro, C. Rainieri, and G. Fabbrocino, "Structural and seismic monitoring of the 'cardarelli' Hospital in Campobasso," in Procedia Engineering, 2017.

[23] A. F. Kamarudin et al., "Structural health monitoring on medium rise reinforced concrete building using ambient vibration method," in IOP Conference Series: Earth and Environmental Science, 2018.

[24] A. Nguyen, K. A. T. L. Kodikara, T. H. T. Chan, and D. P. Thambiratnam, "Toward effective structural identification of medium-rise building structures,” J. Civ. Struct. Heal. Monit., 2018.

[25] N. J. Savnik, E. I. Katsanos, S. D. R. Amador, C. E. Ventura, and R. Brincker, "Influence of diaphragm modelling on the dynamic performance of a reinforced concrete high-rise building," in Proceedings of ISMA 2018 - International Conference on Noise and Vibration Engineering and USD 2018 - International Conference on Uncertainty in Structural Dynamics, 2018.

[26] M. H. Cheng and T. H. Heaton, "Simulating building motions using ratios of the building's natural frequencies and a timoshenko beam model,” Earthq. Spectra, 2015.

[27] V. V. Krylov, "Control of traffic-induced ground vibrations by placing heavy masses on the ground surface," J. Low Freq. Noise Vib. Act. Control, 2007.

[28] D. Gunn, G. Williams, H. Kessler, and S. Thorpe, "Rayleigh wave propagation assessment for transport corridors,” Proc. Inst. Civ. Eng. Transp., 2015. 